DR LEVI OBIJIOFOR is a senior lecturer in journalism at the School of Journalism and Communication, University of Queensland, Brisbane, Australia.

\section{Story telling as the hub of investigative reporting}

Story-based Inquiry: A manual for investigative journalists, by Mark Lee Hunter, Nils Hanson, Rana Sabbagh, Luuk Sengers, Drew Sullivan, Flemming Tait Svith and Pia Thordsen. Paris: UNESCO. 2011, 87 pp. ISBN 9789231041891 (pbk).

$\mathrm{N}$ THIS book, Story-based in-
quiry: A manual for investigative journalists, authors Mark Lee Hunter, Nils Hanson, Rana Sabbagh, Luuk Sengers, Drew Sullivan, Flemming Tait Svith and Pia Thordsen present detailed, systematic and practical processes and procedures through which journalists can engage in investigative reporting. The authors acknowledge that, like all human activities, investigation consumes time, money and energy, but at the end it is worth the effort. This manual, published by the UNESCO

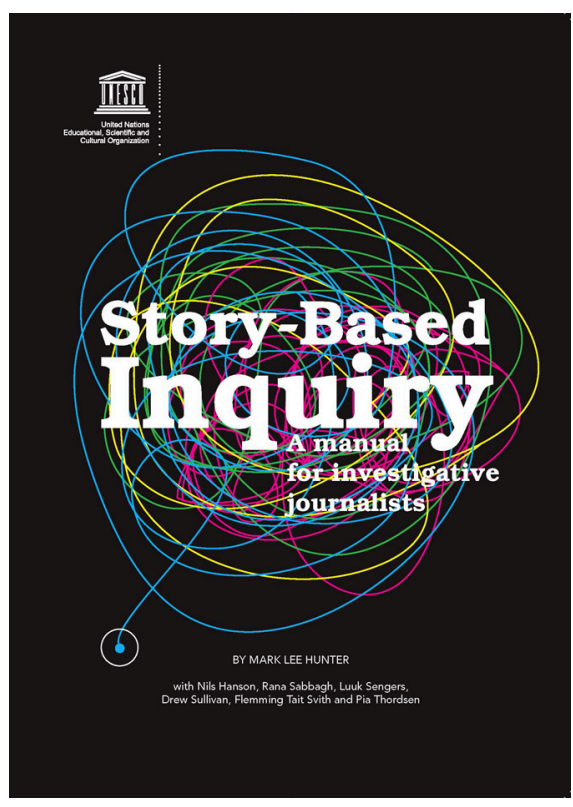

head office in Paris, represents a major contribution to the literature on investigative journalism.

The authors argue that, although the process of investigative reporting might appear as simple as the conventional news story, it is a much more delicate and sensitive process that must adhere to the canons of ethical and quality journalism practice. The authors draw on their vast experiences to explain how stories constitute the building blocks of investigative reporting. This is the approach they refer to as 'hypothesis-based inquiry' which starts with a hypothetical formulation of ideas about a story a journalist wants to confirm or disprove. 
While many texts on investigative journalism tend to concentrate on explaining how the journalist can access information, this manual differs from others because it perceives and treats story telling as the hub of investigative reporting.

The book is divided into eight short chapters. Chapter 1 examines investigative reporting as a subject. To the question-What is investigative journalism? - the authors responded: 'Investigative journalism involves exposing to the public matters that are concealed-either deliberately by someone in a position of power, or accidentally, behind a chaotic mass of facts and circumstances that obscure understanding. It requires using both secret and open sources and documents' (p. 8).

The authors argue that investigative reporting should not be conceived as, and confused with, our understanding of conventional reporting. They distinguish between standard news reporting (which is based essentially or completely on 'materials provided by others') and investigative reporting which relies on material collected or initiated by the journalist through their own resourcefulness. The manual identifies various sources of investigative stories. They include: monitoring media contents, monitoring events in our environment, as well as listening to and monitoring the public sphere in order to draw up a list of public complaints.

In Chapter 2, the authors examine the process of formulating a hypothesis to investigate a story. In their words, a 'hypothesis is a story and a method for testing it' (p. 14). Five advantages of hypothesis-driven investigation are outlined but the authors warn that 'Hypothesis-based investigation is a tool that can dig up a lot of truth, but it can also dig a deep grave for the innocent' (p. 17).

Chapter 3 examines the various sources that journalists can use to conduct investigations. They include 'open' sources such as information in the media, information held in university libraries, information held by government agencies, government libraries, courts, company reports, tribunals or registers of companies and so on. Chapter 4 discusses how journalists can use human sources and includes valuable information on how the journalist should prepare for their first contact with their sources, how to start and uphold meaningful relationship with the sources; the chapter also examines effective strategies for interviewing sources.

Collection and organisation of data is the subject of Chapter 5. As investigation produces more material than standard news reporting, it 
follows that accumulation of massive data in the process of investigation would require the journalist to develop effective strategies to manage the data as the investigation proceeds. In Chapter 6, the authors deal with the process of writing the report after collecting data. The writing process requires different skills, different creative principles and different writing styles. The chapter discusses the elements of style and how to avoid turgidity in writing. The authors recommend two narrative forms of writing-chronological and picaresque narrative. In the former, the journalist orders events by time. In the latter, the journalist orders events by place. The authors endorse the use of any of the two forms of narrative.

Chapter 7 examines the elements of quality control which include checking and crosschecking facts and ethics to ensure accuracy and to eliminate redundancies. Chapter 8 , the final chapter, discusses the value of editing the story, illustrating the story with effective graphics or photographs, and casting the correct headline for the story.

Anyone interested in the art and science of investigative reporting will find this manual a highly valuable and practical resource. The manual does not just explain what investigative reporting is all about, it tells the reader how to do it. I strongly recommend the text to journalism educators, journalism students, professional journalists and citizen journalists who might be attracted to investigative reporting.

One of the major strengths of the manual is its simplicity and brevity, including the systematic and detailed guidelines about how to engage in investigative reporting. These elements are what distinguish this manual from the plethora of books on investigative journalism. 